\title{
Erratum to: Effects of the Antibiotics Chlortetracycline and Enrofloxacin on the Anaerobic Digestion in Continuous Experiments
}

\author{
A. Bauer ${ }^{1,2}$ - J. Lizasoain ${ }^{1,2}$ - E. Nettmann ${ }^{3}$ - I. Bergmann ${ }^{4}$ - K. Mundt ${ }^{4}$ - M. Klocke ${ }^{4}$. \\ M. Rincón ${ }^{1} \cdot$ T. Amon ${ }^{5} \cdot$ G. Piringer ${ }^{1} \cdot$ C. Winckler ${ }^{1}$
}

Published online: 28 December 2015

(C) Springer Science+Business Media New York 2015

Erratum to: Bioenerg Res (2014)

DOI 10.1007/s12155-014-9458-0

The original version of this article unfortunately contained mistakes in the authorship. The author's name, "Christoph Winckler" as the 10th author, is missing. The correct version is presented above.

The online version of the original article can be found at http://dx.doi.org/ $10.1007 / \mathrm{s} 12155-014-9458-0$.

\footnotetext{
A. Bauer

alexander.bauer@boku.ac.at
}

1 Department of Sustainable Agricultural Systems, University of Natural Resources and Applied Life Sciences, Konrad Lorenz Strasse 24, 3430 Tulln, Austria

2 AlpS-Gmbh, Centre for Climate Change Adaptation Technologies, Grabenweg 68, 6020 Innsbruck, Austria

3 Lehrstuhl für Siedlungswasserwirtschaft und Umwelttechnik, Ruhr-Universität Bochum, Universitätstrasse 150, 44801 Bochum, Germany

4 Abt. Bioverfahrenstechnik, Leibniz-Institut für Agrartechnik, Potsdam-Bornim e.V. (ATB), Max-Eyth-Allee 100, 14469 Potsdam, Germany

5 Abt. Technik in der Tierhaltung, Leibniz-Institut für Agrartechnik, Potsdam-Bornim e.V. (ATB), Max-Eyth-Allee 100, 14469 Potsdam, Germany 